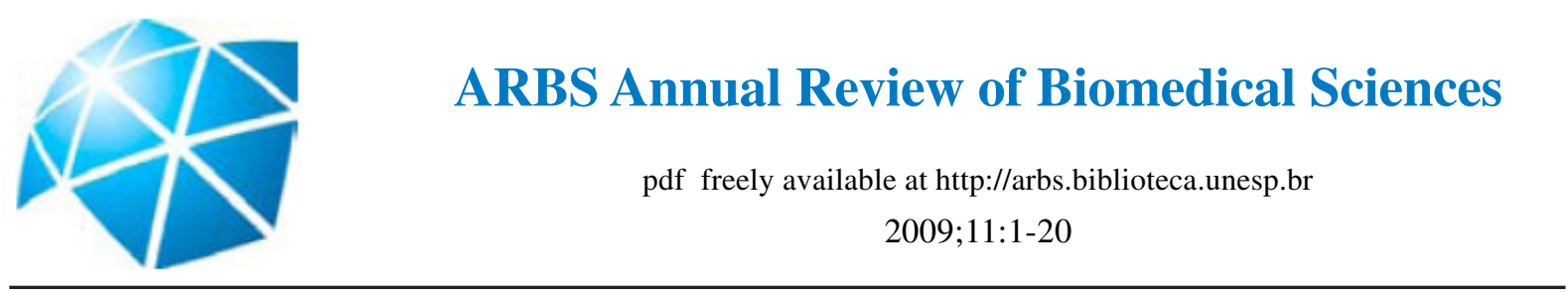

\title{
Psychological Stress and Welfare in Fish
}

\author{
Leonor Galhardo $^{1 *}$, Rui F Oliveira ${ }^{1,2}$ \\ ${ }^{1}$ Unidade de Investigação em Eco-Etologia, Instituto Superior de Psicologia Aplicada, Lisboa, \\ PORTUGAL \\ ${ }^{2}$ Instituto Gulbenkian de Ciência, Oeiras, PORTUGAL
}

Received: 23 December 2008; accepted 09 February 2009

Online on 03 March 2009

\begin{abstract}
Galhardo L, Oliveira RF. Psychological Stress and Welfare in Fish. Annu Rev Biomed Sci 2009;11:1-20. The ability to respond to stress is vital to the survival of any living organism, though sustained reactions can become detrimental to the health and welfare of animals. Stress responses of vertebrates are known through several studies in their physiological, behavioural and psychological components, under acute and chronic contexts. In fish, the physiological and behavioural aspects of stress are considerably well known phenomena and show striking similarities to those of other vertebrates. However, the psychological component is not well known. Some authors deny mental experiences to fish on the basis of their lack of neocortex. Nevertheless, recent studies have shown neuroendocrine, cognitive and emotional processes in fish that are not only equivalent to other vertebrates, but also allow inferring some forms of mental representation. The integration of psychological elements in fish stress physiology is insufficiently studied, but, as discussed in this article, there is already indirect evidence to admit that some form of stimuli appraisal can take place in fish. This fact has profound implications on the regulation of the stress response, as well as on fish welfare and its management.

Oby São Paulo State University - ISSN 1806-8774
\end{abstract}

Keywords: psychological stress, fish welfare, stress responses

\section{Table of Contents}

1. Introduction

2. Evolution of the 'Psychological Stress' Concept

3. Physiological Response to Stress in Fish

3.1. Homeostasis and allostasis

3.2. The three stages of the stress response

3.3. The sympatho-adrenergic response

3.4. The HPI axis response

3.5. The coordination between the sympatho-adrenergic and the HPI axes

4. Behavioural Response to Stress in Fish

\section{* Correspondence}

Leonor Galhardo. Unidade de Investigação em Eco-Etologia, Instituto Superior de Psicologia Aplicada, Rua Jardim do Tabaco, 34 1149-041 Lisboa, Portugal, and Instituto Gulbenkian de Ciência, R. Quinta Grande 6, 2780156 Oeiras, Portugal. E-mail: leonor_galhardo@ispa.pt

Rui F Oliveira: rui.oliveira@ispa.pt 
4.1. Behavioural responses to acute stress

4.2. Behavioural responses during chronic stress

5. Factors Influencing the Stress Response

5.1. Individual-related

5.2. Stressor-related

6. Physiological Integration of Psychological Components of Stress

6.1. The stimuli appraisal in humans

6.2. The neuroendocrine regulation at the higher level of the brain in mammals

7. Indicators of the Psychological Stress in Fish

7.1. Neuroendocrine processes

7.2. Cognitive processes (learning and memory)

7.3. Emotional processes (pain and fear)

8. Psychological Modulators of the Stress Response

8.1. Stimuli-related modulators: predictability and social support

8.2. Response-related modulators: control and outlets for frustration

9. Implications of Psychological Stress to Fish Welfare

9.1. Psychological stress and welfare

9.2. Managing the psychological stress in fish

10. References

\section{Introduction}

A wide range of stimuli challenges a fish around the clock, whether in captivity or in the wild. These stimuli may be life threatening, a novel event deserving exploration or a source of discomfort. They may be real or not, immediate or anticipated, and even adjusted according to the individual perception of the animal. In any case, these challenging stimuli (stressors) demand a response, which is the essence of coping and adapting to a given environment. Generally termed stress responses, they are essential for the organisms' survival. Animals unable to turn their response system on may find themselves in trouble. However, those unable to turn them off may also suffer damages of various extents (Sapolsky, 1992).

The physiological and behavioural responses to stress are very well studied in many teleost species, having striking similarities to those of other vertebrates (Barton, 1997; Sumpter, 1997). Despite the modern concept of stress being inextricably linked to mental processes, only recently it was assumed that fish stress also has a psychological dimension (Barton, 1997). Limited research has focused in the involved mechanisms, but some interesting data already exist on the relationship between stress and learning processes (e.g. Schreck et al., 1997; Moreira et al., 2004; Moreira \& Volpato, 2004). There is also a growing body of evidence that fish have complex mental processes shaping their behavioural responses (Chandroo et al., 2004b; Braithwaite \& Boulcott, 2008; Pottinger, 2008). These facts have relevant implications for fish welfare considerations, since the animals' perception of their own circumstances is a key aspect of the whole concept of welfare (Dawkins, 1990, 2004). Therefore, this review integrates the current knowledge of physiological and behavioural aspects of stress in fish with the recent findings related to fish mental mechanisms which may influence both the stimuli perception and the stress response. The implication of the psychological component of stress to fish welfare will be discussed, namely in terms of opportunities for their better management in captivity.

\section{Evolution of the 'Psychological Stress' Concept}

The basic idea of psychological stress is as old as the Greek classical philosophers. Epicurus suggested that coping with emotional factors was a way to improve the 'quality' of life (Johnson et al., 1992). But it was much later that these factors became fully integrated in the concept of stress.

In 1859, Claude Bernard first introduced the idea of 'milieu interieur', which had to be kept harmonious in response to the external changes (Johnson et al., 1992). Further exploring this, Walter Cannon developed the concept of homeostasis: a relatively stable condition by which the body maintains its internal balance (Cooper \& Dewe, 2004). Threatened by any environmental stimulus, including 
those of emotional nature, the body prepares for action through the activation of the sympathetic nervous system (Levine, 2005). This preparation to the 'fight-or-flight' response mobilises energy required to restore the threatened or effectively lost homeostasis. Cannon's ideas, put forward in the first half of the century and never using the word 'stress', gave a major contribution to the understanding of homeostatic and stress mechanisms. In 1956, Hans Selye described his concept of stress and the 'General Adaptation Syndrome', giving great relevance to the adrenal cortex response (Levine, 2005). This consisted of three stages: 'alarm', in which the body mobilises its defence mechanisms; 'resistance', including various forms of tissue damage if the stressor persists; and 'exhaustion', when the adaptive energy is depleted, potentially causing death. While being the first acknowledging psychological elements of the stress concept, Cannon and Selye highlighted the non-specificity of the stress response, regardless the nature of the stressor (Cooper \& Dewe, 2004).

In the seventies, Mason was the first questioning the generality of the stress response and the lack of relevance given to psychological factors in explaining it (Cooper \& Dewe, 2004). He mentioned the likelihood of a higher involvement of the central nervous system in what he called the "emotional arousal to a threat", which could possibly modulate the stress response (Cooper \& Dewe, 2004; Veissier $\&$ Boissy, 2007). The contribution of Richard Lazarus, in the second half of the twentieth century, was a milestone to the modern concept of stress. Based on his work for the military in the Second World War, he claimed that individual differences in stress responses were based on the respective 'personal meaning' attached to particular events. The concept of 'appraisal' became a central piece of his work: a somewhat 'enriched' perception also involving a personal evaluation, which is dependant on individual goals and beliefs (Lazarus, 1999). The appraisal process detects the stimuli and prepares the body to react, consisting in two stages: the primary appraisal or the process of evaluating the personal relevance of a given stimuli, and the secondary appraisal or the process of assessing the available coping options. His contribution is highly founded in interconnected cognitive and emotional mechanisms, but he also acknowledges that some appraisals can be extremely rapid and unconscious, leading to fast coping responses (Lazarus, 1999). Other appraisal-related theories were developed, mainly differing on the types of criteria that contribute to the evaluation process (Désiré et al., 2002).

More recently, Ursin \& Eriksen (2004) presented their 'Cognitive Activation Theory of Stress' (CATS), formally defining some concepts frequently used in confounding terms (e.g. coping, hopelessness, helplessness). The stress response involves neurophysiological activation and arousal and it is regarded as a healthy process, if not sustained over time. A major aspect of this theory is the assumption that the stress response depends on learned expectancies related to the stimuli and to the result of the available coping resources. These expectancies are, as will be developed later in this article, the major source of individual differences in the stress response (Eriksen et al., 2005).

\section{Physiological Response to Stress in Fish}

\subsection{Homeostasis and allostasis}

More recently, Cannon's concept of homeostasis was changed into what Sapolsky (2004) called the 'homeostasis plus': the notion of allostasis. Meaning "stability through change", allostasis introduces a more dynamic and flexible view of the internal balance (McEwen, 1998). According to different life cycle stages (breeding, migrating, molting, etc.), the internal balance is reshaped to accommodate different requirements. The organism is able to anticipate predictable changes through feedforward mechanisms (e.g. breeding season) and has also responses to unpredictable changes through feedback mechanisms (e.g. a fight with a rival). The means through which it copes with all these environmental inputs require a set of physiological and behavioural processes coordinated by the brain. These may be used differentially in accordance to the nature of the imposed changes and have a biological cost of different levels (allostatic load) (McEwen \& Wingfield, 2003). Animals in allostatic overload are considered to be within the pathological dominion, which is when stress becomes maladaptive and a real concern in terms of welfare (Moberg, 1985; McEwen, 1998; Broom 2008). 


\subsection{The three stages of the stress response}

The stress response in fish is very similar to that of other vertebrates and can be described in three stages (Barton, 2002; Iwama, 2007). The primary response involves the activation of two neuroendocrine axes. The hypothalamus-sympathetic-chromaffin cell axis produces cathecolamines (adrenaline and noradrenaline) from the chromaffin cells, the equivalent of adrenal medulla in tetrapods. The second axis is the hypothalamic-pituitary-interrenal tissue (HPI) axis, with the production of corticosteroids (mainly cortisol, in teleosts) from the interrenal tissue, the equivalent of adrenal cortex in tetrapods. The interrenal tissue surrounds the dorsal posterior cardinal (DPC) veins of the anterior kidney, with the chromaffin cells scattered within it and in the walls of the DPC veins (Janz \& Weber, 2000). The sympatho-adrenergic response activates cardiovascular and respiratory functions and assists in the mobilisation of energy stores for the increased metabolic requirements (Sumpter, 1997). As in the other vertebrates, the HPI response is related to the energy metabolism and hydromineral balance (Mommsen et al., 1999).

The secondary response is a physiological and behavioural adjustment to the stress conditions. It includes the activation of a number of metabolic pathways which induce a wide range of changes in blood chemistry and haematology, respiration, acid-base disturbances with ion losses at the gills, hydrothermal balance, cellular response and immune function (McDonald \& Milligan, 1997; Barton, 2002; Iwama, 2007). It has been demonstrated that there is a close relationship between the immune system and the stress response, with glucocorticoids having a strong anti-inflammatory effect and inducing relevant changes in immune cells, as well as cytokines having the power to stimulate the cortisol production (Fulford \& Harbuz, 2005). In fish these interactions are also present, with the anterior kidney being the common site for haematopoiesis, antibody and stress hormones production (Weyts $e t$ al., 1999). A number of enzymes and metabolic products, immune system function, blood glucose as well as heatshock proteins have been used to measure this response, despite a certain degree of inconsistency in some of them (Broom \& Johnson, 1993; Mommsen et al., 1999; Iwama, 2007).

The tertiary response, has to do with the prolonged stressor exposure, and refers to changes in the whole organism, having an eventual impact in the population (Iwama, 2007). Stress has inhibitory effects on fish reproduction and inhibits growth due to metabolic effects and by affecting growth endocrine pathways (Pankhurst \& Van Der Kraak, 1997). Overall resistance to disease can also suffer profound changes and lead to immune suppression, dramatically increasing the disease's incidence and mortality rates (Broom \& Johnson, 1993; McDonald \& Milligan, 1997).

\subsection{The sympatho-adrenergic response}

In the presence of a stressor the sympathetic nervous system is activated by means of autonomic neurons coming from the paraventricular nucleus (PVN) of the hypothalamus to the locus coeruleus in the brainstem and spinal cord (Peter, 1990). The chromaffin cells are stimulated by the sympathetic preganglionic fibers via cholinergic receptors to release stored catecholamines (Sumpter, 1997). In teleost fish, adrenaline has the most important role in the stress response (Barton, 2002). Within seconds, the combined action of the sympathetic nerves and adrenaline prepares the body tissues with $\beta$ adrenoreceptors for 'fight or flight'; accelerating heart and respiration rate, increasing blood pressure and flow at the muscles, and stimulating glucose release (Peter, 1990). The activity of the parasympathetic nervous system becomes suppressed in these emergency times - energy storage, digestion or growing are automatically 'judged' as luxuries in a body with higher priorities (Sapolsky, 2004).

During acute stress, catecholamine's concentration decreases in a few minutes, but if the stressor is prolonged it can remain high for longer periods of up to some days. Chronic stress can induce desensitisation of the system or impairment in catecholamine storage (Sumpter, 1997).

\subsection{The HPI axis response}

The first level of the HPI cascade is the hypothalamus. The hypothalamic preoptic nucleus (PON) secretes the peptide corticotrophin-releasing hormone $(\mathrm{CRH})$, which belongs to a very relevant family of hormones, known as the CRH system, and is present in all vertebrates (Janz \& Weber, 2000; 
Chen \& Fernald, 2008). This includes a number of related peptides also involved in the HPI regulation and expressed in a number of important central and peripheral tissues. Even though CRH's mechanisms of action are still not entirely understood, its control upon adrenocorticotrophic hormone (ACTH) release is well established (Huising \& Flik, 2005; Flik et al., 2006). In turn, a variety of neurotransmitters and cytokines are able to stimulate the synthesis of CRH (Johnson et al., 1992). Arginine vasotocin (AVT) is also produced by the hypothalamus, with likely differences in the subsets of neurons involved and in the way they modulate the HPI response (Balment et al., 2006). Other neuropeptides can interact with $\mathrm{CRH}$ neurons and in this way influence subsequent hormone production.

The second level of the HPI axis is the pituitary gland. The pituitary cells are innervated directly by the hypothalamic neurosecretory fibres (Peter, 1990). CRH and AVT act synergistically to enhance ACTH production at the anterior pituitary (corticotrophs). The presence of AVT allows an increased flexibility over ACTH control as CRH and AVT gene expression are regulated independently (Balment et al., 2006). ACTH is secreted very rapidly in response to a stressor and it may fall back to the basal levels during prolonged exposure showing that habituation occurs above the level of the pituitary gland (Sumpter, 1997). CRH also controls the release of $\alpha$-melanocyte stimulating hormone $(\alpha-M S H)$ and $\beta$ endorphin from the melanotrophs at the intermediate lobe of the pituitary (Sumpter, 1997; Huising et $a l ., 2005)$. $\beta$-endorphin is an agonist of opiate receptors in the nervous system, producing analgesia and regulating moods (Lovallo, 2005). It has been suggested that $\alpha$-MSH and $\beta$-endorphin can act in synergy with ACTH for the cortisol synthesis (Sumpter, 1997).

The third level of the HPI axis is the interrenal tissue, which produces cortisol upon ACTH (and other hormones) stimulation (Barton, 2002). It is generally agreed that cortisol rises after the exposure to a stressor within the first 4-10 minutes and lasts for a few hours (Foo \& Lam, 1993; Sumpter, 1997). When fish are subjected to chronic stress, plasma cortisol can be elevated for many days or even weeks or may return to basal levels due to habituation mechanisms or impairment of the HPI axis (Sumpter, 1997; Hontela, 1998; Barton, 2002).

Cortisol is a fundamental hormone for the maintenance of allostasis as it has both a permissive role (it permits other hormones to accomplish their function in basal conditions) and a stress-induced regulatory role (Johnson et al., 1992). There are two types of known cortisol receptors: the mineralocorticoid receptors (MR) and the glucocorticoid receptors (GR). In mammals, MR receptors are sensitive to low levels of cortisol, being responsible for body fluid balance, for cortisol negative feedback over the diurnal cycle and to the normal metabolic glucose demands (De Kloet et al., 2005; Lovallo, 2005). The GR receptors have much less affinity to cortisol, only detecting it if in very high concentrations, and thus they are more related to the stress response and its recovery (Johnson et al., 1992). Until recently, teleosts were thought to have only GR receptors with both osmotic and stressrelated functions (Mommsen et al., 1999). However, MR receptors were recently described in common carp (Prunet et al., 2006; Stolte et al., 2008). Transactivation studies show that both receptors have similar affinities to cortisol, despite the main MR ligand is still not entirely defined (Stolte et al., 2008). Expression of GRs and MRs mRNA was found in the forebrain (especially in the lateral pallium) and in all relevant neuroendocrine components of the HPI axis, in a very similar pattern to that described in other vertebrates (De Kloet et al., 2005; Stolte et al., 2008). The role of these receptors in the forebrain and in the homologous limbic areas in mammals will be discussed below. The HPI is regulated by a series of negative feedback loops, with cortisol mainly acting back at the hypothalamus, pituitary gland and interrenal tissue to inhibit CRH, ACTH and its own synthesis (Sumpter, 1997). However, other hormones, neurotransmitters and cytokines also contribute to the HPI regulation (Johnson et al., 1992).

\subsection{The coordination between the sympatho-adrenergic and the HPI axes}

The sympatho-adrenergic response and the HPI axis interact with each other, in order to avoid excessive activation of each system and concomitant negative consequences (Johnson et al., 1992). Hypothalamic neuronal projections activate sympathetic outputs leading to the adrenaline release. This hormone is indirectly regulated by autonomic reflexes and by cortisol feedback to the hypothalamus, which reduces activation of brainstem sympathetic brain centres (Lovallo, 2005). CRH and ACTH synthesis may be in turn activated by catecholamines (Johnson et al., 1992). 


\section{Behavioural Response to Stress in Fish}

\subsection{Behavioural responses to acute stress}

The first alarm response is an essential aspect of the behavioural response (Ursin \& Eriksen, 2004). The arousal response affects sensory, perceptual and cognitive mechanisms, serving the purpose of narrowing the attention to a given source of threat (Steckler, 2005). This attentive state favours the retrieval of acquired memories and the acquisition of new ones. As it will be discussed later on, this is fundamental to produce the most appropriate response to a given stressor. During the arousal, the sympathetic system is turned on, while all behaviours commanded by the parasympathetic are switched off. The animal interrupts what it is doing, whether swimming around, feeding or exploring and directs its attention to the stressor.

In response to the stressor, the inhibitory behavioural system is one of the possible defensive systems to be activated. It occurs in conflict contexts and contributes to increased vigilance and arousal, frequently leading to enhanced exposure to the stressor (Steckler, 2005). In fish, as described by a number of authors, the most paradigmatic response of this type is the freezing behaviour during which the animal remains motionless on the bottom, with no fin movement (e.g. Vilhunen \& Hirvonen, 2003). This behaviour may occur, for example, as a defensive mechanism against fear (e.g. Yue et al., 2004), or as an anti-predator defence (e.g. Vilhunen \& Hirvonen, 2003). However, as it will be discussed later, this coping strategy is not exclusively context-dependent; personality types or other specificities can activate this or other defensive systems.

Fully opposed to freezing-like behaviours is the fight-or-flight defensive mechanism with the active purpose of removing the threat imposed by the stressor, whether by acting over it or by moving away (Schreck et al., 1997; Steckler, 2005). A number of different fish behavioural patterns have been related to this defensive system (Huntingford et al., 2006; Ashley \& Sneddon, 2008). In response to a threatening event, they may include protective motor reactions like flee, hide or shoaling. Aggressive responses are also extensively described and include chases and attacks of variable intensities (e.g. Oliveira \& Almada, 1998). Body rocking and rubbing against surfaces were described as nociceptive and pain responses (Sneddon et al., 2003a). Locomotory patterns are also sensitive to many stressors, and much used in behavioural analysis (Huntingford et al., 2006). A number of environmental factors, like exposure to noxious chemicals, water temperature, etc., may affect the effectiveness of the fight-orflight response (Schreck et al., 1997).

\subsection{Behavioural responses during chronic stress}

When behavioural defence mechanisms are not enough to remove the animal from the source of threat, changes of behaviour in a larger scope may occur, reflecting the imposed allostatic load over the animal. Schreck and colleagues (1997) reviewed the range of fish behaviours that may be affected during exposure to chronic stress. Beyond significant changes in the swimming patterns, sustained levels of stress can decrease or change the anti-predator behaviour, disrupt feeding behaviour, increase shelter seeking (sometimes in an inappropriate manner), change territorial behaviour and, as will be discussed later, interfere with learning processes (Schreck et al., 1997).

\section{Factors Influencing the Stress Response}

Depending on a number of factors, the neuroendocrine systems responds differently in speed, magnitude and patterning of hormones and neurotransmitters activity, as well as in behavioural patterns (Sapolsky, 2004; Lovallo, 2005). Differences in individual and stressor related aspects will be discussed below.

\subsection{Individual-related}

Barton (2002) reviewed a number of environmental, genetic and developmental factors that may account for different endocrine responses. The state of the internal and external individual's environment may alter the stressors' effect and the response. The magnitude of the cortisol response 
also varies with species, even if closely related, between wild and domesticated fish, and among strains or stocks. Sex differences were found between females and immature males of rainbow trout, with females recovering from stress quicker than males (Øverli et al., 2006). Developmental factors also account for relevant differences to stress vulnerability. Stress responses develop early in life and may have long-lasting effects (Barton, 2002; Flik et al., 2006). Auperin and Geslin (2008) just demonstrated that early exposure to a brief stressor reduced the cortisol response later in life in rainbow trout.

The definition of coping styles in fish greatly contributed to the understanding of individual differences in the stress responses (Koolhaas et al., 1999; Øverli et al., 2002). Two copying styles have been defined due to their consistent neuroendocrine and behavioural characteristics: the reactive (shy) and the pro-active (bold) coping response. The first is characterised by higher levels of cortisol release and by inhibitory behaviours such as freezing. The latter is typical of the fight-and-flight response with lower levels of cortisol production. Shy individuals tend to be less aggressive and eventually subordinate, while the bold are predictably dominants and more aggressive (Pottinger \& Carrick, 2001; Øverli et al., 2004a). However, these clear-cut distinctions may be flexible or even disappear in certain contexts or as a result of experience (Schjolden et al., 2005; Brown et al., 2007; Frost et al., 2007).

\subsection{Stressor-related}

The stressors that may affect the life of a fish both in natural conditions and in captivity have been reviewed by a number of authors (e.g. Schreck et al., 1997; Conte, 2004; Huntingford et al., 2006). The relevance of a stressor to an individual has not only to do with its nature, but also with the pattern of exposure (Broom \& Johnson, 1993). Intensity and duration are two main attributes to take into consideration, but also the effect of repeated stressors or the length of time left between discrete stressors (Barton, 2002).

There is no clear-cut distinction between physical and psychological stressors as most of them involve both components, though in variable proportions (Steckler, 2005). Lovallo (2005) distinguishes them as those that start out in the body (physical) and those that start out in the mind (psychological), being the cortisol response particularly sensitive to the psychological stressors in mammals. In fish, one major source of psychological stress is the social environment due to the formation of hierarchies and the competition for territories and social partners. Many studies have been evaluating the effect of social status and social stressors on the HPI axis and other related systems (e.g. Munro \& Pitcher, 1985; Fox et al., 1997; Pottinger \& Carrick, 2001; Clement et al., 2005; Gilmour et al., 2005; Earley et al., 2006; Fernandes-De-Castilho et al., 2008). Social stressors may primarily elicit fear, danger recognition and anticipation of threatening events with concomitant neuroendocrine responses (Chandroo et al., 2004a). Other relevant sources of potentially strong psychological components are those related to husbandry procedures in captivity.

However, even more important than the physical or psychological nature of the stressors per se, are the individual appraisals (Ursin \& Eriksen, 2004). This purely psychological mediator between any stressor and the stress response is the responsible for major sources of variability to stress vulnerability. This aspect will be discussed separately in a subsequent section.

\section{Physiological Integration of Psychological Components of Stress}

Psychological stress depends primarily on the ability to appraise the stimuli in two steps. Firstly, they are perceived and evaluated in relation to their properties and specific importance, and secondly coping mechanisms will be mentally assessed in preparation to the effective bodily reaction (Lazarus, 1999; Ursin \& Eriksen, 2004). In humans, this mechanism has been well described (e.g. Lovallo, 2005), and is summarised in this section. Some authors already applied this framework to farm animals in their studies of emotions (e.g. Désiré et al., 2002; Boissy et al., 2007). In fish, the regulation of stress involving psychological components is not well studied and there is even a current debate about whether fish possess sufficient psychological capacities for mental assessment of stressful situations (e.g. Rose 2002, 2007). However, there is a body of indirect indicators supporting the possibility that fish may develop similar mental processes. These will be discussed in a subsequent section. 


\subsection{The stimuli appraisal in humans}

The sensory information is received by frontal areas of the cortex, where a cognitive evaluation of the stimulus takes place, and by the limbic system (hippocampus and amygdala), where it is emotionally coloured (Lovallo, 2005). The frontal areas of the cortex are specialised in working memory, required for the cognitive assessment of the inputs. The hippocampus is known to be important in the formation of non-emotional memory (e.g. spatial memory) and in the recall of familiar events (declarative memory), while the amygdala invokes contextual aspects of these events through its particularly important role in classical conditioning (emotional memory) (Prickaerts \& Steckler, 2005). By attributing an emotional context, the amygdala modulates the consolidation of long-term memories at the hippocampus (Akirav \& Richter-Levin, 2005). It is activated whenever the affective value of a stressor, signalled by a conditioned stimulus, has to be assessed. Its emotional output is then sent to the frontal cortex, through basal ganglia pathways, where it is integrated with the cognitive evaluation of the stimulus in the cingulate cortex (Lovallo, 2005). This cortical structure then elaborates on the choices to make under a given motivational context sending projections back to the amygdala (Steckler, 2005).

The appraised information is then sent to the hypothalamus and brainstem by either the central nuclei of the amygdala or the pre-frontal cortex (Lovallo, 2005). The outputs of the amygdala have an extensive indirect effect on a number of peripheral responses, namely on behaviours involved in the stress response (e.g. arousal, attention, freezing, fear, conflict, etc.) (Akirav \& Richter-Levin, 2005). Therefore, the subsequent signals of the lateral nuclei and paraventricular nuclei of hypothalamus and of the different structures of the brainstem will express the emotional valence of the received stimulus, through the activation of the autonomic, neuroendocrine and behavioural responses. In the brainstem, a complex feedback system, composed by descending and ascending actions of the reticular formation and aminergic nuclei and the CRF system of neurons, coordinates the behavioural arousal, emotional profile and general state of the brain, having the CRF a particularly important role in the integration of the acute fight-or-flight response (Lovallo, 2005).

\subsection{The neuroendocrine regulation at the higher level of the brain in mammals}

In mammals, there are MR and GR receptors in a number of cortical (prefrontal cortex) and limbic areas (amygdala and hippocampus), located especially in CRH neurons. This fact suggests that the regulation of the stress response does not always start at the level of the hypothalamus and brainstem. Rather, whenever there are sensory inputs and the need for their interpretation as described above, the stress response starts at the frontal cortex, amygdala and hippocampus (De Kloet et al., 2005). Noradrenaline, through noradrenergic pathways, is also important for this high level regulation, as it indirectly inputs in the amygdala, influencing arousal and various memory mechanisms (Berridge, 2005).

Normally, cortisol at the hippocampus exerts an inhibitory effect at the hypothalamic paraventricular nucleus, via GABAergic neurons which form a net surrounding it. At the amygdala, cortisol has a contrary effect, since it inhibits GABAergic neurons at the hypothalamus, in this way activating the HPA axis and generating a positive feedback in the cortisol production (De Kloet et al., 2005). It is apparent that prolonged effects of corticosteroids switches cognitive improvement into impairment (Akirav \& Richter-Levin, 2005). Therefore, the influence of their action at the higher levels of the brain during acute stress is different from those under chronic stress. Acute elevations of glucocorticoids enhance memory consolidation and retrieval, and possibly attention, at the level of GR receptors mainly in the hippocampus but also in the amygdala (Prickaerts \& Steckler, 2005). During chronic stress, sustained high levels of corticoids reduce the hippocampus volume, which impairs learning and memory and seem to disrupt attentional mechanisms (Lovallo, 2005). Prolonged cortisol exposure has the additional effect of disrupting the hippocampus inhibitory influence over the hypothalamus, in this way stimulating the HPA axis and the further production of cortisol (De Kloet et al., 2005).

\section{Indicators of the Psychological Stress in Fish}

Despite the lack of knowledge on the precise mechanisms underlying the integration of psychological aspects in the stress physiology of fish, a growing body of evidence shows the existence 
of mental processes in these animals. This is however a matter of controversy since, to some authors, the lack of neocortex is a number one reason to deny any form of consciousness to fish (Rose, 2002, 2007; Iwama, 2007). Furthermore, only very simple forms of learning (habituation, simple classical conditioning) were traditionally attributed to fish, all regulated at the brainstem level (Rodriguez et al., 2006). The concomitant behaviour was interpreted as simple and relatively stereotyped.

However, behavioural, cognitive and neuroanatomic studies, developed in the last decades, revealed a very different picture concerning the behaviour and underlying mechanisms in fish, with implications to the discussion of whether or not fish can have at least simple forms of consciousness. They are capable of highly flexible and specialised behaviour, depending from complex neuroendocrine, cognitive and emotional processes (for reviews see Bshary et al., 2002; Braithwaite \& Huntingford, 2004; Chandroo et al., 2004a; Ashley \& Sneddon, 2008; Braithwaite \& Boulcott, 2008).

\subsection{Neuroendocrine processes}

Stimuli appraisal requires the detection of sensory inputs, and the generation of mental representations which involve both working and declarative memory and associated emotional states. As described above, in mammals the related neural substrate is the limbic system, in particular the amygdala and hippocampus, and various areas of the prefrontal cortex. In fish, the sensory information is received by the forebrain, which - just like the mammalian cortex - processes and coordinates motor outputs (Butler \& Hodos, 2005). The lateral pallium and the medial pallium are the identified homologous structures to the hippocampus and amygdala respectively, as demonstrated in recent research on spatial memory of goldfish (Rodriguez et al., 2006). Using a number of learning paradigms, these studies showed evidence of complex memory formation and retrieval in emotional and non-emotional contexts (Lopez et al., 2000; Vargas et al., 2000; Portavella et al., 2003). The lack of mammalian-like cortex in fish is not a necessary condition to deny them some form of awareness, and thus some form of appraisal, since the central nervous system shows so many homologies and similar mechanisms to those of higher vertebrates (Butler \& Hodos, 2005). Furthermore, as mentioned before, consciousness does not arise in one precise site in the mammalian brain. It is the result of an intricate system of neuronal connections with specific characteristics that work together in producing conscious thoughts and in keeping the allostasis of the central nervous system (Taylor, 2001; Lovallo, 2005). These interconnections also occur in fish and involve homologous neuronal areas, and similar chemicals and mechanisms (e.g. dopaminergic and serotonergic brain systems) (Chandroo et al., 2004a). The possibility of some analogies within the brain should also be considered (Bshary et al., 2002; Chandroo et al., 2004b).

The exact neuroendocrine mechanisms of the fish stress responses above the level of the hypothalamus are still not well known. However, corticosteroid receptors were recently found in forebrain areas, namely in the lateral pallium. This fact suggests that these brain areas - like in mammals - are the primary targets during stress control, having than a potential consequence to fish cognitive processes (Stolte et al., 2008).

\subsection{Cognitive processes (learning and memory)}

The cognitive capabilities of fish have been extensively reviewed (e.g. Bshary et al., 2002; Braithwaite \& Huntingford, 2004; Chandroo et al., 2004a; Braithwaite, 2006). It has been argued that mental representations of the declarative type are necessary for consciousness (Taylor, 2001; Chandroo et al., 2004a). The ability for this in fish is shown in the most varied contexts. Individual recognition in the social network and subsequent behavioural adjustment, as well as prey-predator relationships are well studied topics (Braithwaite, 2006). In agonistic encounters there is also evidence of mental representations: fighting fish extract and use information obtained from the observation of other fishes' fights (Eavesdrop in Oliveira et al., 1998; McGregor et al., 2001). Androgenic activity may be triggered by the mere observation of a fight in Mozambique tilapia (Oliveira et al., 2001) and by the perception of the fights' outcome and not by the fight itself (Oliveira et al., 2005). Also using a fighting context, Grosenick and colleagues (2007) have shown how Astatotilapia burtoni is capable of transitive inference, an advanced reasoning skill until recently only attributed to primates, rats and pigeons (Wynne, 2001). 
Spatial learning and memory have also been studied, with evidence of great behavioural flexibility involving multiple learning and memory systems, part of which require spatial mental representations (cognitive maps) (Odling-Smee \& Braithwaite, 2003; Rodriguez et al., 2006). The memory of timeplace associations is one of the pre-requisites for episodic memory, and has also been demonstrated for a number of species (Reebs, 1996, 1999; Barreto et al., 2006a; Delicio \& Barreto, 2008). Fish avoidance of dangerous sites, showing anticipatory capabilities, was already described in different studies (Huntingford \& Wright, 1989; Kelley \& Magurran, 2003).

Schreck and colleagues (1997) reviewed a number of studies showing how stress can affect the memory and learning processes in fish. The memory induced by a stress context was demonstrated more recently by Moreira \& Volpato (2004) in Nile tilapia with a conditioned endocrine response to confinement (unconditioned stimulus) signalled by light (conditioned stimulus). A similar investigation was undertaken with rainbow trout, selectively bred for divergent plasma cortisol responses. Retention of a conditioned response was longer in the low than in the high responsive fish, showing that different cortisol responses correspond to different cognitive profiles (Moreira et al., 2004). A subsequent study confirmed that exogenous cortisol accelerated the extinction of a conditioned response in unselected rainbow trout (Barreto et al., 2006b). These findings were in line with the above mentioned detection of cortisol receptors in areas of the forebrain responsible for memory.

\subsection{Emotional processes (pain and fear)}

The emotional colouration of the stimuli is what confers them relevance. It is an essential part of the appraisal process and it is also what shapes motivation and subsequent behaviour in any given moment (Lazarus, 1999). Due to the lack of language, the subjective state of a given emotion cannot be studied in animals in the same way as it is in humans. Therefore, the correspondent physiological and behavioural responses are the focus of the research on emotions (Ashley \& Sneddon, 2008).

In fish, the study of emotions has been especially focused in pain and fear. Lynne Sneddon and colleagues (Sneddon, 2003; Sneddon et al., 2003a) have described not only the nociceptive system of rainbow trout, but also the pain perception through non-reflexive behaviour and physiological responses. They found that morphine had an analgesic effect, reducing pain-related behaviours and opercular beat. Ashley and Sneddon (2008) reviewed studies involving opiate production, as mediators of nociception and pain, and their specific receptors in fish.

Sneddon and her team (2003b) have shown how familiarisation with novel objects can reduce the typical fear response of rainbow trout (as described above). Based on the same experimental paradigm, these researchers showed how rainbow trout limit their attention to a novel object when under a painful condition, and how this behaviour can be reversed by the administration of a pain-killer (morphine). Avoidance learning tasks are a common paradigm in fear research, revealing a consistent pattern of avoidance behaviours (e.g. Portavella et al., 2003; Yue et al., 2004). Yue and colleagues (2004) have shown how the behavioural responses of rainbow trout to fearful stimuli are of a non-reflexive nature and how they can make conscious choices to avoid future frightening stimuli. Ashley and Sneddon (2008) review studies where the administration of benzodiazepines (anti-anxiety drugs) to fish can reduce the typical fear response.

The influence of corticosteroids in defensive behaviours related to fear and anxiety was reviewed by Korte (2001) in studies undertaken in rats. This author describes how these hormones can accelerate the extinction of conditioned fear responses by the occupation of different corticosteroid receptors at variable moments of the stress response. Despite the unknown exact mechanism, Barreto and colleagues (2006b) seem to have observed the same in a paradigm that most certainly involve fear (partial emersion), and where fish with implanted cortisol retained the learned response for less time.

\section{Psychological Modulators of the Stress Response}

As mentioned throughout this article, one of the most, if not the most, relevant reasons accounting for the differential stress responses is the way the stressor is appraised (Sapolsky, 2004; Ursin \& Eriksen, 2004; Steckler, 2005). This fact has implications not only on the perception of the stimuli but also on 
the evaluation of the available coping responses (Lazarus, 1999; Ursin \& Eriksen, 2004). According to the Cognitive Activation Theory of Stress, these two appraisal stages are associated to specific internal expectancies (set values) which are compared with the reality (actual value). The degree of the resulted discrepancy dictates the level of arousal and the related stress response (Ursin \& Eriksen, 2004). However, the expectancies can be cognitively manipulated by modifying the psychological context in which the stressor is applied. This manipulation can be linked to the stimulus appraisal or to the coping responses appraisal.

\subsection{Stimuli-related modulators: predictability and social support}

The predictability of a stressor affects the stress response and this fact has been extensively described for humans and animals (Sapolsky, 2004; Lovallo, 2005). Despite the inconsistent physiological responses of various studies, it is apparent that animals prefer predictable negative events over unpredictable ones (Bassett \& Buchanan-Smith, 2007). For example, in rats different predictable stressors alleviate stress responses and promote place preferences and spatial learning (Orsini et al., 2002; Prior, 2002). Fish also seem to be sensitive to this psychological variable. Studies conducted in Mozambique tilapia showed higher levels of cortisol when subjected to a signalled unpredictable over predictable confinement (Galhardo \& Oliveira, unpublished data). It has been suggested that predictability produces less arousal due to a sense of safety during periods of non-signalisation (Bassett \& Buchanan-Smith, 2007). Additionally, predictability provides some sense of control, as it allows self-preparation to the incoming event, even if only internally and not by means of behaviour (Orsini et al., 2002). However, the relieving effect of predictability depends a great deal on a number of stressor's properties (nature, intensity and frequency) as well as on the reliability of the signalling system and on the time elapsed between the sign and the onset of the aversive event (Sapolsky, 2004). For example, it is highly unlikely that the anticipation of a very damaging event will alleviate the stress response in the same way that a very frequent event does not benefit from an additional warning.

Social support creates a psychological context where the stress response is much reduced and where animals show better welfare (DeVries et al., 2003; Sapolsky, 2004). In fish, familiarity has been studied in relation to shoal formation and dynamics. Despite the inherent costs, shoals benefit individuals in terms of antipredator protection, better foraging efficiency and finding mating partners (Pitcher $e t$ al., 1982; Magurran, 1990; Swaney et al., 2001). The ability to recognize and preferentially associate with familiar individuals is widespread in fishes (reviewed by Griffiths, 2003; Griffiths et al., 2004). It is known that familiarity promotes social learning, cooperation, cohesion and less aggression (Swaney et al., 2001; Bhat \& Magurran, 2006). It is well identified that both isolation and group formation with unfamiliar conspecifics enhance behavioural and physiological responses to stress in social mammals (e.g. Gust et al., 1996; Jensen, 2001; Ruis et al., 2001; DeVries et al., 2003; Takeda et al., 2003; Désiré et al., 2006). In fish, the same effect has been shown: social isolation increases cortisol levels and modifies the feeding and agonistic patterns of interaction (Earley et al., 2006; Øverli et al., 2006) and encounters with unfamiliar fish also produces a cortisol response (Yue et al., 2006). A number of studies, especially undertaken in primates, have shown how social support can ameliorate the adverse effect of a stressor (Johnson et al., 1996; Sapolsky, 2004). In fish, specifically in Mozambique tilapia, social support has increased exploration, showing a reduction in fear and anxiety levels induced by a novel object (Galhardo \& Oliveira, unpublished data). However, the presence of tank mates did not relieve the stress response of Mozambique tilapia to confinement (Galhardo \& Oliveira, unpublished data), suggesting that the effect of social support may also depend on the nature of the stressor (DeVries et al., 2003).

\subsection{Response-related modulators: control and outlets for frustration}

Control is understood as the capability to successfully decrease the exposure to a stressor. It has been regarded as an important factor for the subject's judgment of its coping possibilities (Steckler, 2005), and thus it is a relevant modulator of the stress responses. However, providing an animal with an actual degree of control may be not enough for their positive appraisal of the coping outcome. The self evaluation of possible coping responses is limited by prior experiences (Ursin \& Eriksen, 2004). Thus, 
if prior responses were successful in removing the source of stress, the animal acquires a sense of control that will lower its level of arousal and keep it prepared to cope with following challenges (Eriksen et al., 2005). This is probably one of the reasons why dominant fish tend to have lower cortisol levels than subordinates (Earley et al., 2006) and may also be one of the cognitive contributes to the 'winner and loser effect' (Eriksen et al., 2005), where winners have a higher probability of winning a subsequent encounter (Rutte et al., 2006). Frost and colleagues (2007), for example, have shown how bold rainbow trout reduced their boldness as a consequence of negative prior experiences (loosing fights). On the other hand, if the animal learned from past experiences that there was no relationship between its attempts to cope and the outcome result of the stress experience (total lack of control), it may develop learned helplessness, a condition that has been associated to depression (Ursin \& Eriksen, 2004; Lovallo, 2005). Under this state, the animals may be unable to realise that objective control is eventually available and that they could make use of it; learning and avoidance responses becomes impaired (Steckler, 2005). Ursin and Eriksen (2004) distinguish helplessness from hopelessness, in which the latter means some form of negative control, where the response may even contribute to worsen the stressful situation, and consider it a better depression model. Both conditions are known to be powerful in cortisol activation (Ursin \& Eriksen, 2004; Lovallo, 2005) and it is possible that subordinate fish may frequently find themselves in these circumstances (Earley et al., 2006).

Outlets for frustration distract the subject from the stressor (Sapolsky, 2004). Typically, the behavioural responses do not help to remove the source of stress, but they do probably give the animal a perception that it is doing something about it. In this way, they contribute to alleviate the adverse effect of the stressor, as shown by the decreased physiological signs of stress. Examples of possible outlets for frustration are the displacement activities (maybe including self-directed behaviours) and eventually stereotypies. Sapolsky (2004) gives the example of exercise and displaced aggression as powerful outlets for human frustration. Displaced aggression is understood as aggression that, in the impossibility of being directed towards the original aggressor (dominant), it is targeted towards weaker conspecifics (e.g. smaller animals, females) or even towards elements of the environment (e.g. substrate). This type of aggression is also common in non-humane primates. Studies with baboons, conducted by Sapolsky and his team, found subsets of subordinates, which displaced aggression and showed low levels of cortisol (DeVries et al., 2003). In fish, displaced aggression as an outlet for stressful social encounters was also observed. Øverli and his team (2004b) have shown how rainbow trout facing larger animals reacts against smaller fish, with patterns of brain serotonin and plasma cortisol compatible with decreased stress. Clement and colleagues (2005) also found, with Astatotilapia burtoni, that territorial males engaged in directed aggression (towards a dominant male in a video display) and non-territorial males directed their aggression towards the tank mates. The physiological correlate of this study is though less clear, as two subsets of cortisol levels were found for the non-territorial males. Outlets for aggression in the form of interactions with substrate have also been suggested by other authors for different cichlid species (Munro \& Pitcher, 1985; Galhardo et al., 2008). The stereotypes' performance is an additional outlet for frustration. Mason and Latham (2004) have suggested a number of underlying mechanisms for these repetitive and invariable behaviours. Some of them are particularly suggestive of alternative coping strategies to deal with non-controllable stressors, since the performance of these behaviours reduced the response to stress. In fish, Ashley (2007) mentions some studies where the locomotory pattern of Atlantic salmon and Atlantic halibut resembles the pacing in mammals. However, these mechanisms are still not well studied in fishes.

\section{Implications of Psychological Stress to Fish Welfare}

\subsection{Psychological stress and welfare}

The stress concept is extremely linked to that of welfare. Poor welfare occurs when coping mechanisms fail to adjust the organism to its environment (Broom, 2008). Adaptation should not be seen only as a homeostatic mechanism always ready to be triggered in response to threats. A more dynamic view considers the body preparation in anticipation to predictable changes. This allostatic view, defended by Korte and colleagues (2007), is extremely important to the welfare concept: what is relevant is the animals' ability to change their coping strategies in anticipation and along with incoming 
challenges. These efficient adjustment mechanisms require the fine coordination of a brain and all the organs under its command. For that purpose, appraisal processes have a marked role in evaluating the nature and importance of those challenges.

A mental mediation of stress has profound implications to the welfare of animals. Welfare can be defined in terms of physical functioning, behavioural nature and subjective experiences (Appleby, 1999). For some authors, it is in the dominion of the mental experiences that welfare assumes all its relevance as a concept (Dawkins, 1990; Duncan \& Fraser, 1997). The fact that the animals can have the perception of their own situation is what makes the difference between welfare and health. Thus, poor welfare means a reduced ability to cope with environmental challenges, which is associated not only to the actual situation in which the animals find themselves but also to how they appraise it.

The studies described in this article have provided arguments in favour of some form of appraisal process in fish. They receive and process sensory stimuli, they seem to form mental representations, being capable of relatively complex forms of learning and memory and they show the potential for emotional states (pain and fear). Dawkins (2001) calls the attention to a number of pitfalls in trying to understand consciousness in animals. One of these is the temptation of assigning complex cognitive features to the existence of consciousness. In her words, we "do not need to be very clever to feel pain or hunger or fear". However, some authors have shown how the study of cognition can provide useful insights to the understanding of consciousness (Mendl \& Paul, 2004). For example, the ability for mental time travel, requiring in humans episodic memory and future thinking, was found in a species of bird, the European scrub jays (Clayton \& Dickinson, 1999). Episodic memory implies the ability to store and recall a memory of 'what-where-when' events, in a structured and flexible way. The existence of this type of memory in animals, associated to the consciousness of unique events in the past, has consequences for their welfare (Mendl \& Paul, 2008). That is, an animal capable of forming episodic memory can anticipate future events, preparing for them in a very flexible way, but also suffer in anticipation. It is known that fish can anticipate events, like avoiding predator sites (e.g. Kelley \& Magurran, 2003) or showing feeding anticipation (Galhardo \& Oliveira, unpublished data). While these behaviours may be mediated by simpler forms of learning, experimental work has shown already that some species form at least relational memories of the type 'where-when' (Reebs, 1996, 1999; Barreto et al., 2006a; Delicio \& Barreto, 2008).

On the basis of the complexity that psychological stress and welfare may involve, their evaluation requires careful procedures. As discussed throughout this article, the same stressor may elicit very different coping responses in different individuals or even in the same individual in different contexts or stages of its life. Therefore, as the coping physiological and behavioural responses are usually used as indicators of stress and welfare, these need to be interpreted with caution and having full regard for their precise context.

\subsection{Managing the psychological stress in fish}

One obvious aspect of promoting psychological well-being in captivity is the conception of artificial environments free from pain and fear. However, this is almost never possible due to the very nature of the artificial settings and handling procedures. Nevertheless, at the same time that certain pain and fear-enhancing elements can be abolished or reduced, the memory and learning abilities of fish can also be used to reduce their impact. For example, Schreck and colleagues (1995) conditioned chinook salmon to associate feeding to prior handling and transport. As a consequence, these animals have shown a reduced physiological response to stress, an improved fitness during transport and a better coping response when exposed to additional stressors. Thus, positive reinforcement training can buffer the adverse impact of stressors with advantages for fish and other vertebrates' well-being (Laule \& Desmond, 1998).

Operant conditioning techniques can provide means for environmental control, which as discussed above, is an important variable modulating psychological stress. For example, provision of correctly adjusted self-feeders (operated by the fish) may promote growth and feed conversion ratios in rainbow trout (Alanara, 1996). One of the control components is the ability for choosing between options. Providing appropriate environmental features allows this choice and possibly a positive 
perception of successful coping ability (Eriksen et al., 2005). In carp, the provision of hiding material to undertake avoidance behaviour in face of a threatening olfactory cue, reduced the physiological response to stress and allowed the avoidance behaviour (Hoglund et al., 2005). Additionally, an appropriately enriched environment can provide animals with outlets for frustration. As mentioned above, substrate eventually regulates levels of aggression in captivity and can provide an enlarged scope for foraging in environments that are poorer than the natural ones (Munro \& Pitcher, 1985; Galhardo et al., 2008).

Predictability is another aspect that can change the perception of threatening stimuli. Considering that it potentially modifies fish coping responses, its manipulation can reduce the negative impact of certain stressful procedures. To be noted, however, that in line with other studies reviewed by Bassett and Buchanan-Smith (2007), predictability for positive events may have a different impact on the fish response. In fact, presenting tilapia with predictable food does not alter its cortisol response, despite the clear exhibition of anticipatory behaviours, when compared to unpredictable food delivery (Galhardo \& Oliveira, unpublished data). A generalised idea in the environmental enrichment research is that excessive predictability may enhance symptoms of boredom, reason why the controlled presentation of novel stimuli is favoured (Bassett \& Buchanan-Smith, 2007; Morgan \& Tromborg, 2007). Therefore, it seems reasonable to admit that for a good husbandry, predictable or unpredictable events must be managed on a case-by-case basis and in relation to their nature, intensity and duration.

Keeping animals in appropriate social groups is a well known stabilising element in captivity as well as a powerful mean of environmental complexity and enrichment (Carlstead, 1996). As mentioned above, since isolation seems to have a negative impact in some fish species, and social support seems to reduce fear, the promotion of adequate social contact can also be used to improve welfare.

Beyond any other considerations, it is important to highlight the important role of an appropriate level of challenges in the promotion of welfare in captivity (Wemelsfelder \& Birke, 1997; Meehan \& Mench, 2007). A prolonged deficit of environmental stimulation may impair mental and physical mechanisms due to chronic lack of opportunities to interact with the environment. Animals may show symptoms of apathy and boredom (Wemelsfelder \& Birke, 1997). On the other hand, excessive environmental stimulation can sensitise coping mechanisms, enhancing permanent arousal and leading to a generalised state of exhaustion, which is the cause of many anxiety-related pathologies (Meehan \& Mench, 2007). Therefore, inappropriate stimulation induces an allostatic overload of different types which is incompatible with good welfare (McEwen \& Wingfield, 2003).

In summary, an adjusted level of environmental complexity, control and predictability, with the concomitant learning opportunities, are very important factors to keep both the mental and physical mechanisms within the boundaries of an acceptable allostatic load. These are likely to be among the most important aspects to contribute for the animals' positive mental attitude towards their environment and hence to their good welfare.

\section{References}

Akirav I, Richter-Levin G. Involvement of the amygdala in the neuroendocrine and behavioral consequences of stress. In: Steckler T, Kalin NH, Reul JMHM (editors). Handbook of Stress and the Brain. Part 1: The Neurobiology of Stress. Amsterdam: Elsevier, 2005.

Alanara A. The use of self-feeders in rainbow trout (Oncorhynchus mykiss) production. Aquaculture 1996;145:1-20.

Appleby MC. What Should We Do About Animal Welfare? Oxford: Blackwell Science, 1999.

Ashley PJ. Fish welfare: current issues in aquaculture. Appl Anim Behav Sci 2007;104:199-235.

Ashley N, Sneddon L. Pain and fear in fish. In: Branson EJ (editor). Fish Welfare. Oxford: Blackwell Publishing, 2008.

Auperin B, Geslin M. Plasma cortisol response to stress in juvenile rainbow trout is influenced by their life history during early development and by egg cortisol content. Gen Comp Endocrinol 2008;158:234-9.

Balment RJ, Lu W, Weybourne E, Warne JM. Arginine vasotocin a key hormone in fish physiology and behaviour: A review with insights from mammalian models. Gen Comp Endocrinol 2006;147:9-16. 
Barreto RE, Rodrigues P, Luchiari AC, Delicio HC. Time-place learning in individually reared angelfish, but not in pearl cichlid. Behav Process 2006a;73:367-72.

Barreto RE, Volpato GL, Pottinger TG. The effect of elevated blood cortisol levels on the extinction of a conditioned stress response in rainbow trout. Horm Behav 2006b;50:484-8.

Barton BA. Stress in finfish: past, present and future - a historical perspective. In: Iwama GK, Pickering AD, Sumpter JP, Schreck CB (editors). Fish Stress and Health in Aquaculture. Cambridge: Cambridge University Press, 1997.

Barton BA. Stress in fishes: A diversity of responses with particular reference to changes in circulating corticosteroids. Integr Comp Biol 2002;42:517-25.

Bassett L, Buchanan-Smith HM. Effects of predictability on the welfare of captive animals. Appl Anim Behav Sci 2007;102:223-45.

Berridge CW. The locus coeruleus-noradrenergic system and stress: modulation of arousal state and state-dependent behavioral processes. In: Steckler T, Kalin NH, Reul JMHM (editors). Handbook of Stress and the Brain. Part 1: The Neurobiology of Stress. Amsterdam: Elsevier, 2005.

Bhat A, Magurran AE. Benefits of familiarity persist after prolonged isolation in guppies. J Fish Biol 2006;68:759-66.

Boissy A, Arnould C, Chaillou E, Désiré L, Duvaux-Ponter C, Greiveldinger L, Leterrier C, Richard S, Roussel S, Saint-Dizier H, Meunier-Salaün MC, Valance D, Veissier I. Emotions and cognition: a new approach to animal welfare. Anim Welfare 2007; (Supplement)16:37-44.

Braithwaite VA. Cognitive ability in fish. In: Sloman KA, Wilson RW, Balshine S (editors). Behav Physiol Fish. Amesterdam: Elsevier, 2006.

Braithwaite VA, Boulcott P. Can fish suffer? In: Branson EJ (editor). Fish Welfare. Oxford: Blackwell Publishing, 2008.

Braithwaite VA, Huntingford FA. Fish and welfare: do fish have the capacity for pain perception and suffering? Anim Welfare 2004;13:S87-S92.

Broom DM. Welfare assessment and relevant ethical decisions: key concepts. Annu Rev Biomed Sci 2008;10:T79-T90.

Broom DM, Johnson KG. Stress and Animal Welfare. London: Chapman \& Hall, 1993.

Brown C, Burgess F, Braithwaite VA. Heritable and experiential effects on boldness in a tropical poeciliid. Behav Ecol Sociobiol 2007;62:237-43.

Bshary R, Wickler W, Fricke H. Fish cognition: a primate's eye view. Anim Cogn 2002;5:1-13.

Butler AB, Hodos W. Comparative Vertebrate Neuroanatomy: Evolution and Adaptation. New Jersey: John Wiley \& Sons, Inc., 2005.

Carlstead K. Effects of captivity on the behavior of wild mammals. In: Kleiman DG, Allen ME, Thompson KV, Lumpkin S (editors). Wild Mammals in Captivity: Principles and Techniques. Chicago: The University of Chicago Press, 1996.

Chandroo KP, Duncan IJH, Moccia RD. Can fish suffer?: perspectives on sentience, pain, fear and stress. Appl Anim Behav Sci 2004a;86:225-50.

Chandroo KP, Yue S, Moccia RD. An evaluation of current perspectives on consciousness and pain in fishes. Fish Fish 2004b;5:281-95.

Chen CC, Fernald RD. Sequences, expression patterns and regulation of the corticotropin-releasing factor system in a teleost. Gen Comp Endocrinol 2008;157:148-55.

Clayton NS, Dickinson A. Memory for the content of caches by scrub jays (Aphelocoma coerulescens). J Exp Psychol Anim Behav Proc 1999;25:82-91.

Clement TS, Parikh V, Schrumpf M, Fernald RD. Behavioral coping strategies in a cichlid fish: the role of social status and acute stress response in direct and displaced aggression. Horm Behav 2005; 47:336-42.

Conte FS. Stress and the welfare of cultured fish. Appl Anim Behav Sci 2004;86:205-23.

Cooper CL, Dewe P. Stress: a Brief History. Oxford: Blackwell Publishing, 2004.

Dawkins MS. From an Animals Point of View - Motivation, Fitness, and Animal-Welfare. Behav Brain Sci 1990;13:1-61.

Dawkins MS. Who needs consciousness? Anim Welfare 2001;10:S19-S29.

Dawkins MS. Using behaviour to assess animal welfare. Anim Welfare 2004;13:S3-S7. 
De Kloet ER, Schmidt M, Meijer OC. Corticosteroid receptors and HPA-axis regulation. In: Steckler T, Kalin NH, Reul JMHM (editors). Handbook of Stress and the Brain. Part 1: The Neurobiology of Stress. Amsterdam: Elsevier, 2005.

Delicio HC, Barreto RE. Time-place learning in food-restricted Nile tilapia. Behav Process 2008;77:126-30.

Désiré L, Boissy A, Veissier I. Emotions in farm animals: a new approach to animal welfare in applied ethology. Behav Process 2002;60:165-80.

Désiré L, Veissier I, Despres G, Delval E, Toporenko G, Boissy A. Appraisal process in sheep (Ovis aries): Interactive effect of suddenness and unfamiliarity on cardiac and behavioral responses. $\mathbf{J}$ Comp Psychol 2006;120:280-7.

DeVries AC, Glasper ER, Detillion CE. Social modulation of stress responses. Physiol Behav 2003;79:399-407.

Duncan IJH, Fraser D. Understanding animal welfare. In: Appleby MC, Hughes BO (editors). Animal Welfare. Oxon: CABI Publishing, 1997.

Earley RL, Edwards JT, Aseem O, Felton K, Blumer LS, Karom M, Grober MS. Social interactions tune aggression and stress responsiveness in a territorial cichlid fish (Archocentrus nigrofasciatus). Physiol Behav 2006;88:353-63.

Eriksen HR, Murison R, Pensgaard AM, Ursin H. Cognitive activation theory of stress (CATS): From fish brains to the Olympics. Psychoneuroendocrino 2005;30:933-8.

Fernandes-De-Castilho M, Pottinger TG, Volpato GL. Chronic social stress in rainbow trout: Does it promote physiological habituation? Gen Comp Endocrinol 2008;155:141-7.

Flik G, Klaren PHM, Van den Burg EH, Metz JR, Huising MO. CRF and stress in fish. Gen Comp Endocrinol 2006;146:36-44.

Foo JTW, Lam TJ. Serum Cortisol Response to Handling Stress and the Effect of Cortisol Implantation on Testosterone Level in the Tilapia, Oreochromis-Mossambicus. Aquaculture 1993;115:145-58.

Fox HE, White SA, Kao MHF, Fernald RD. Stress and dominance in a social fish. J Neurosci 1997; 17:6463-9.

Frost AJ, Winrow-Giffen A, Ashley PJ, Sneddon LU. Plasticity in animal personality traits: does prior experience alter the degree of boldness? Proc R Soc Lond B Biol Sci 2007;274:333-9.

Fulford AJ, Harbuz MS. An introduction to the HPA axis. In: Steckler T, Kalin NH, Reul JMHM (editors). Handbook of Stress and the Brain. Part 1: The Neurobiology of Stress. Amsterdam: Elsevier, 2005.

Galhardo L, Correia J, Oliveira RF. The effect of substrate availability on behavioural and physiological indicators of welfare in the African cichlid (Oreochromis mossambicus). Anim Welfare 2008;17:239-54.

Gilmour KM, DiBattista JD, Thomas JB. Physiological causes and consequences of social status in salmonid fish. Integr Comp Biol 2005;45:263-73.

Griffiths SW. Learned recognition of conspecifics by fishes. Fish Fish 2003;4:256-68.

Griffiths SW, Brockmark S, Hojesjo J, Johnsson JI. Coping with divided attention: the advantage of familiarity. Proc R Soc Lond B Biol Sci 2004;271:695-9.

Grosenick L, Clement TS, Fernald RD. Fish can infer social rank by observation alone. Nature 2007;445:429-32.

Gust DA, Gordon TP, Brodie AR, McClure HM. Effect of companions in modulating stress associated with new group formation in juvenile rhesus macaques. Physiol Behav 1996;59:941-5.

Hoglund E, Weltzien FA, Schjolden J, Winberg S, Ursin H, Doving KB. Avoidance behavior and brain monoamines in fish. Brain Res 2005;1032:104-10.

Hontela A. Interrenal dysfunction in fish from contaminated sites: In vivo and in vitro assessment. Environ Toxicol Chem 1998;17:44-8.

Huising MO, Flik G. The remarkable conservation of corticotropin-releasing hormone (CRH)-binding protein in the honeybee (Apis mellifera) dates the CRH system to a common ancestor of insects and vertebrates. Endocrinology 2005;146:2165-70.

Huising MO, Metz JR, De Mazon AF, Verburg-Van Kemenade BM, Flik G. Regulation of the stress response in early vertebrates. Ann N Y Acad Sci 2005;1040:345-7. 
Huntingford FA, Wright PJ. How Sticklebacks Learn to avoid dangerous feeding patches. Behav Process 1989;19:181-9.

Huntingford FA, Adams C, Braithwaite VA, Kadri S, Pottinger TG, Sandoe P, Turnbull JF. Current issues in fish welfare. J Fish Biol 2006;68:332-72.

Iwama GK. The welfare of fish. Dis Aquat Organ 2007;75:155-8.

Janz DM, Weber L. Endocrine system. In: Ostrander GK (editor). The Laboratory Fish. San Diego, USA: Academic Press, 2000.

Jensen MB. A note on the effect of isolation during testing and length of previous confinement on locomotor behaviour during open-field test in dairy calves. Appl Anim Behav Sci 2001;70:309-15.

Johnson EO, Kamilaris TC, Carter CS, Calogero AE, Gold PW, Chrousos GP. The biobehavioral consequences of psychogenic stress in a small, social primate (Callithrix jacchus jacchus). Biol Psychiatry 1996;40:317-37.

Johnson EO, Kamilaris TC, Chrousos GP, Gold PW. Mechanisms of stress - a dynamic overview of hormonal and behavioral homeostasis. Neurosci Biobehav Rev 1992;16:115-30.

Kelley JL, Magurran AE. Learned predator recognition and antipredator responses in fishes. Fish Fish 2003;4:216-26.

Koolhaas JM, Korte SM, De Boer SF, Van Der Vegt BJ, Van Reenen CG, Hopster H, De Jong IC, Ruis MAW, Blokhuis HJ. Coping styles in animals: current status in behavior and stress-physiology. Neurosci Biobehav Rev 1999;23:925-35.

Korte SM. Corticosteroids in relation to fear, anxiety and psychopathology. Neurosci Biobehav Rev 2001;25:117-42.

Korte SM, Olivier B, Koolhaas JM. A new animal welfare concept based on allostasis. Physiol Behav 2007;92(3):422-8

Laule G, Desmond T. Positive reinforcement training as an enrichment strategy. In: Shepherdson DJ, Mellen JD, Hutchins M (editors). Second Nature: Environmental Enrichment for Captive Animals. Washington: Smithsonian Institution Press, 1998.

Lazarus RS. Stress and Emotion: a New Synthesis. New York: Springer Publishing Company, 1999.

Levine S. Stress: an historical perspective. In: Steckler T, Kalin NH, Reul JMHM (editors). Handbook of Stress and the Brain. Part 1: The Neurobiology of Stress. Amsterdam: Elsevier, 2005.

Lopez JC, Broglio C, Rodriguez F, Thinus-Blanc C, Salas C. Reversal learning deficit in a spatial task but not in a cued one after telencephalic ablation in goldfish. Behav Brain Res 2000;109:91-8.

Lovallo WR. Stress \& Health: Biological and Psychological Interactions. Thousand Oaks: Sage Publications, 2005.

Magurran AE. The adaptive significance of schooling as an antipredator defense in fish. Ann Zool Fenn 1990;27:51-66.

Mason GJ, Latham NR. Can't stop, won't stop: is stereotypy a reliable animal welfare indicator? Anim Welfare 2004;13:S57-S69.

McDonald G, Milligan L. Ionic, osmotic and acid-base regulation in stress. In: Iwama GK, Pickering AD, Sumpter JP, Schreck CB (editors). Fish Stress and Health in Aquaculture. Cambridge, UK: Cambridge University Press, 1997.

McEwen BS. Stress, adaptation, and disease - Allostasis and allostatic load. Neuroimmunomodulation 1998;840:33-44.

McEwen BS, Wingfield JC. The concept of allostasis in biology and biomedicine. Horm Behav 2003;43:2-15.

McGregor PK, Peake TM, Lampe HM. Fighting fish Betta splendens extract relative information from apparent interactions: what happens when what you see is not what you get. Anim Behav 2001;62:1059-65.

Meehan CL, Mench JA. The challenge of challenge: Can problem solving opportunities enhance animal welfare? Appl Anim Behav Sci 2007;102:246-61.

Mendl M, Paul E. Do animals live in the present? Current evidence and implications for welfare Appl Anim Behav Sci 2008;113:357-82.

Mendl M, Paul ES. Consciousness, emotion and animal welfare: insights from cognitive science. Anim Welfare 2004;13:S17-S25. 
Moberg GP. Biological response to stress: key to assessment of animal well-being? In: Moberg GP (editor). Animal Stress. Bethesda: American Physiological Society, 1985.

Mommsen TP, Vijayan MM, Moon TW. Cortisol in teleosts: dynamics, mechanisms of action, and metabolic regulation. Rev Fish Biol Fish 1999;9:211-68.

Moreira PSA, Volpato GL. Conditioning of stress in Nile tilapia. J Fish Biol 2004;64:961-9.

Moreira PSA, Pulman KGT, Pottinger TG. Extinction of a conditioned response in rainbow trout selected for high or low responsiveness to stress. Horm Behav 2004;46:450-7.

Morgan KN, Tromborg CT. Sources of stress in captivity. Appl Anim Behav Sci 2007;102:262-302.

Munro AD, Pitcher TJ. Steroid hormones and agonistic behavior in a cichlid teleost, Aequidens pulcher. Horm Behav 1985;19:353-71.

Odling-Smee L, Braithwaite VA. The influence of habitat stability on landmark use during spatial learning in the three-spined stickleback. Anim Behav 2003;65:701-7.

Oliveira RF, Almada VC. Dynamics of social interactions during group formation in males of the cichlid fish Oreochromis mossambicus. Acta Ethol 1998;1:57-70.

Oliveira RF, Carneiro LA, Canario AVM. No hormonal response in tied fights. Nature 2005;437:207-8.

Oliveira RF, Lopes M, Carneiro LA, Canario AVM. Watching fights raises fish hormone levels - Cichlid fish wrestling for dominance induce an androgen surge in male spectators. Nature 2001;409:475.

Oliveira RF, McGregor PK, Latruffe C. Know thine enemy: fighting fish gather information from observing conspecific interactions. Proc R Soc Lond B Biol Sci 1998;265:1045-9.

Orsini C, Ventura R, Lucchese F, Puglisi-Allegra S, Cabib S. Predictable stress promotes place preference and low mesoaccumbens dopamine response. Physiol Behav 2002;75:135-41.

Øverli O, Korzan WJ, Hoglund E, Winberg S, Bollig H, Watt M, Forster GL, Barton BA, E OV, Renner $\mathrm{KJ}$, Summers $\mathrm{CH}$. Stress coping style predicts aggression and social dominance in rainbow trout. Horm Behav 2004a;45:235-41.

Øverli O, Korzan WJ, Larson ET, Winberg S, Lepage O, Pottinger TG, Renner KJ, Summers CH. Behavioral and neuroendocrine correlates of displaced aggression in trout. Horm Behav 2004b;45:324-9.

Øverli O, Pottinger TG, Carrick TR, Overli E, Winberg S. Differences in behaviour between rainbow trout selected for high- and low-stress responsiveness. J Exp Biol 2002;205:391-5.

$\varnothing$ verli O, Sorensen C, Nilsson GE. Behavioral indicators of stress-coping style in rainbow trout: do males and females react differently to novelty? Physiol Behav 2006;87:506-12.

Pankhurst NW, Van Der Kraak G. Effects of stress on reproduction and growth of fish. In: Iwama GK, Pickering AD, Sumpter JP, Schreck CB (editors). Fish Stress and Health in Aquaculture. Cambridge: Cambridge University Press, 1997.

Peter RE. Direct neural regulation of the teleost adenohypophysis. J Exp Zool 1990;(Supplement) 4:84-9.

Pitcher TJ, Magurran AE, Winfield IJ. Fish in Larger Shoals Find Food Faster. Behav Ecol Sociobiol 1982;10:149-51.

Portavella M, Salas C, Vargas JP, Papini MR. Involvement of the telencephalon in spaced-trial avoidance learning in the goldfish (Carassius auratus). Physiol Behav 2003;80:49-56.

Pottinger T. The stress response in fish - mechanisms, effects and measurement. In: Branson EJ (editor). Fish Welfare. Oxford: Blackwell Publishing, 2008.

Pottinger TG, Carrick TR. Stress responsiveness affects dominant-subordinate relationships in rainbow trout. Horm Behav 2001;40:419-27.

Prickaerts J, Steckler T. Effects of glucocorticoids on emotion and cognitive processes in animals. In: Steckler T, Kalin NH, Reul JMHM (editors). Handbook of Stress and the Brain. Part 1: The Neurobiology of Stress. Amsterdam: Elsevier, 2005.

Prior H. Effects of predictable and unpredictable intermittent noise on spatial learning in rats. Behav Brain Res 2002;133:117-24.

Prunet P, Sturm A, Milla S. Multiple corticosteroid receptors in fish: from old ideas to new concepts. Gen Comp Endocrinol 2006;147:17-23.

Reebs SG. Time-place learning in golden shiners (Pisces: Cyprinidae). Behav Process 1996;36:253-62. 
Reebs SG. Time-place learning based on food but not on predation risk in a fish, the inanga (Galaxias maculatus). Ethology 1999;105:361-71.

Rodriguez F, Broglio C, Duran E, Gomez A, Salas C. Neural mechanisms of learning in teleost fish. In: Brown C, Laland K, Krause J (editors). Fish Cognition and Behaviour. Oxford: Blackwell Publishing, 2006.

Rose J. The neurobehavioral nature of fishes and the question of awareness and pain. Rev Fish Sci 2002;10:1-38.

Rose JD. Anthropomorphism and 'mental welfare' of fishes. Dis Aquat Organ 2007;75:139-54.

Ruis MAW, te Brake JHA, Engel B, Buist WG, Blokhuis HJ, Koolhaas JM. Adaptation to social isolation - acute and long-term stress responses of growing gilts with different coping characteristics. Physiol Behav 2001;73:541-51.

Rutte C, Taborsky M, Brinkhof MW. What sets the odds of winning and losing? Trends Ecol Evol 2006;21:16-21.

Sapolsky RM. Cortisol concentrations and the social significance of rank instability among wild baboons. Psychoneuroendocrino 1992;17:701-9.

Sapolsky RM. Why Zebras Don't Get Ulcers. New York: Henry Holt and Company, 2004.

Schjolden J, Backstrom T, Pulman KGT, Pottinger TG, Winberg S. Divergence in behavioural responses to stress in two strains of rainbow trout (Oncorhynchus mykiss) with contrasting stress responsiveness. Horm Behav 2005;48:537-44.

Schreck CB, Jonsson L, Feist G, Reno P. Conditioning improves performance of juvenile Chinook salmon, Oncorhynchus tshawytscha, to transportation stress. Aquaculture 1995;135:99-110.

Schreck CB, Olla BL, Davis MW. Behavioral responses to stress. In: Iwama GK, Pickering AD, Sumpter JP, Schreck CB (editors). Fish Stress and Health in Aquaculture. Cambridge: Cambridge University Press, 1997.

Sneddon LU. Trigeminal somatosensory innervation of the head of a teleost fish with particular reference to nociception. Brain Res 2003;972:44-52.

Sneddon LU, Braithwaite VA, Gentle MJ. Do fishes have nociceptors? Evidence for the evolution of a vertebrate sensory system. Proc R Soc Lond B Biol Sci 2003a;270:1115-21.

Sneddon LU, Braithwaite VA, Gentle MJ. Novel object test: Examining nociception and fear in the rainbow trout. J Pain 2003b;4:431-40.

Steckler T. The neuropsychology of stress. In: Steckler T, Kalin NH, Reul JMHM (editors). Handbook of Stress and the Brain. Part 1: The Neurobiology of Stress. Amsterdam: Elsevier, 2005.

Stolte EH, de Mazon AF, Leon-Koosterziel KM, Jesiak M, Bury NR, Sturm A, Savelkoul HFJ, van Kemenade BMLV, Flik G. Corticosteroid receptors involved in stress regulation in common carp, Cyprinus carpio. J Endocrinol 2008;198:403-17.

Sumpter JP. The endocrinology of stress. In: Iwama GK, Pickering AD, Sumpter JP, Schreck CB (editors). Fish Stress and Health in Aquaculture. Cambridge: Cambridge University Press, 1997.

Swaney W, Kendal J, Capon H, Brown C, Laland KN. Familiarity facilitates social learning of foraging behaviour in the guppy. Anim Behav 2001;62:591-8.

Takeda KI, Sato S, Sugawara K. Familiarity and group size affect emotional stress in Japanese Black heifers. Appl Anim Behav Sci 2003;82:1-11.

Taylor JG. What do neuronal network models of the mind indicate about animal consciousness? Anim Welfare 2001;10:S63-S75.

Ursin H, Eriksen HR. The cognitive activation theory of stress. Psychoneuroendocrino 2004;29:567-92.

Vargas JP, Rodriguez F, Lopez JC, Arias JL, Salas C. Spatial learning-induced increase in the argyrophilic nucleolar organizer region of dorsolateral telencephalic neurons in goldfish. Brain Res 2000;865:77-84.

Veissier I, Boissy A. Stress and welfare: two complementary concepts that are intrinsically related to the animal's point of view. Physiol Behav 2007;92:429-33.

Vilhunen S, Hirvonen H. Innate antipredator responses of Arctic charr (Salvelinus alpinus) depend on predator species and their diet. Behav Ecol Sociobiol 2003;55:1-10.

Wemelsfelder F, Birke L. Environmental challenge. In: Appleby MC, Hughes BO (editors). Animal Welfare. Oxon, UK: CABI Publishing, 1997. 
Weyts FAA, Cohen N, Flik G, Verburg-van Kemenade BML. Interactions between the immune system and the hypothalamo-pituitary-interrenal axis in fish. Fish Shellfish Immunol 1999;9:1-20.

Wynne CDL. Animal Cognition: the Mental Lives of Animals. New York: Palgrave Macmillan, 2001.

Yue S, Duncan IJH, Moccia RD. Do differences in conspecific body size induce social stress in domestic rainbow trout? Environ Biol Fish 2006;76:425-31.

Yue S, Moccia RD, Duncan IJH. Investigating fear in domestic rainbow trout, Oncorhynchus mykiss, using an avoidance learning task. Appl Anim Behav Sci 2004;87:343-54. 